\title{
Mathematical Multibody Model of a Soft Mounted Induction Motor Regarding Forced Vibrations Due to Dynamic Rotor Eccentricities Considering Electromagnetic Field Damping
}

\author{
Ulrich Werner \\ Faculty of Electrical Engineering, Precision Engineering, Information Technology, Georg Simon Ohm University of Applied \\ Sciences, Nuremberg, Germany \\ Email: ulrich.werner@th-nuernberg.de
}

How to cite this paper: Werner, U. (2017) Mathematical Multibody Model of a Soft Mounted Induction Motor Regarding Forced Vibrations Due to Dynamic Rotor Eccentricities Considering Electromagnetic Field Damping. Journal of Applied Mathematics and Physics, 5, 346-364.

https://doi.org/10.4236/jamp.2017.52032

Received: October 25, 2016

Accepted: February 14, 2017

Published: February 17, 2017

Copyright $\odot 2017$ by author and Scientific Research Publishing Inc. This work is licensed under the Creative Commons Attribution International License (CC BY 4.0).

http://creativecommons.org/licenses/by/4.0/

\begin{abstract}
The paper presents a mathematical multibody model of a soft mounted induction motor with sleeve bearings regarding forced vibrations caused by dynamic rotor eccentricities considering electromagnetic field damping. The multibody model contains the mass of the stator, rotor, shaft journals and bearing housings, the electromagnetic forces with respect of electromagnetic field damping, stiffness and internal (rotating) damping of the rotor, different kinds of dynamic rotor eccentricity, stiffness and damping of the bearing housings and end shields, stiffness and damping of the oil film of the sleeve bearings and stiffness and damping of the foundation. With this multibody model, the bearing housing vibrations and the relative shaft vibrations in the sleeve bearings can be derived.
\end{abstract}

\section{Keywords}

Induction Motor, Electromagnetic Field Damping, Rotordynamics, Soft Mounting

\section{Introduction}

Fast running induction motors with high power ratings, $\left(P_{N}>1 \mathrm{MW}\right.$; $n_{N} \geq 2900 \mathrm{rpm}$ ) are often equipped with sleeve bearings, because of the high circumferential speed of the shaft journals, and are often mounted on soft foundations (Figure 1). A soft foundation may be realized by e.g. rubber elements under the motor feet to decouple the motor from the foundation. But also a steel frame foundation can be often characterized to be soft, because of the light weight 
construction. Vibrations of rotating machines are often an issue [1]-[10].

To guarantee a safe operation, the vibrations at the sleeve bearings are often monitored [1] [2] [3]. Usually the relative shaft displacements between the shaft journals and the bearing shells are measured, using induction sensors. Additionally also the bearing housing vibrations may be measured by accelerations sensors (Figure 2).

Increasing requirements in standards and specifications of electrical machines regarding vibration limits [11] [12] [13] [14]—e.g. IEC 60034-14, ANSI/API 541, ISO 10816, ISO 7919-require high sophisticated calculation methods. In addition to the mechanical excitation-e.g. mechanical unbalance [1] [2] [3] - also magnetic forces occur which may lead to high vibrations [4]-[10]. In industry, these magnetic forces are nowadays still considered without the electromagnetic field damping effect, when analyzing the vibrations. The aim of the paper is now to present a multibody model for a soft mounted induction motor and to present a practical way how to consider electromagnetic field damping.

\section{Dynamic Rotor Eccentricity}

The three most important dynamic eccentricities for induction motors-eccentricity of rotor mass, bent rotor deflection and magnetic eccentricity-are here considered in the paper (Figure 3) [9] [10].

- Eccentricity of rotor mass $\hat{e}_{u}$ which is e.g. caused by residual unbalance, which remains after the balancing process.

Stator with

end shields

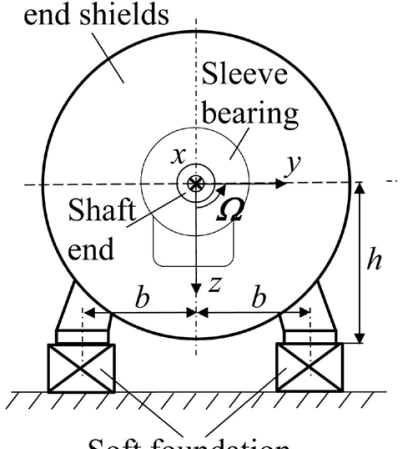

Soft foundation

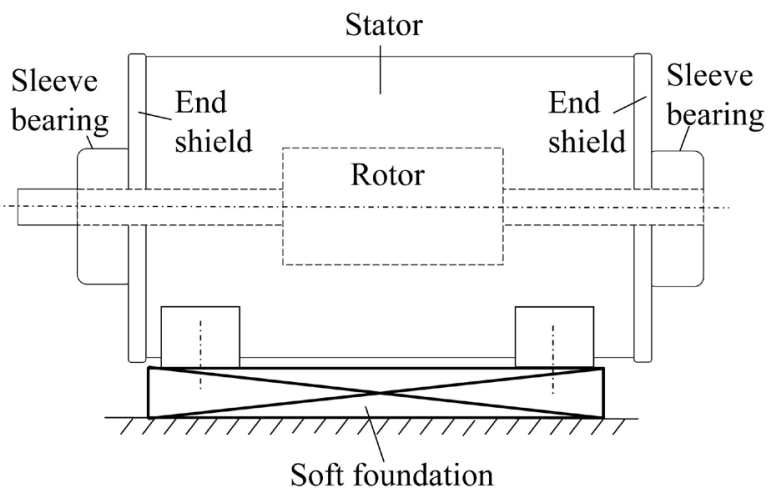

Figure 1. Induction motor with sleeve bearings on a soft foundation.

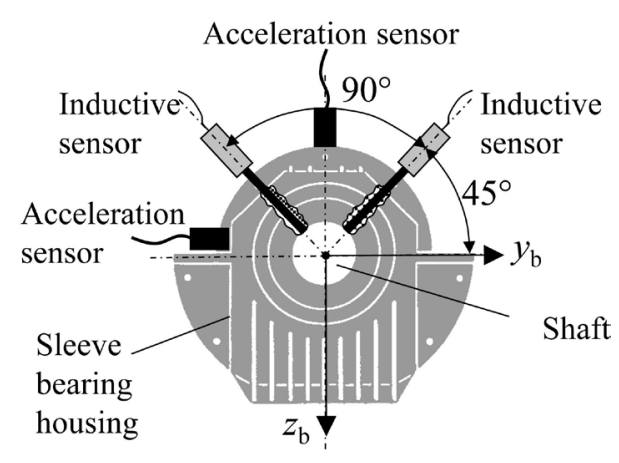

Figure 2. Sensors at the sleeve bearing housing. 


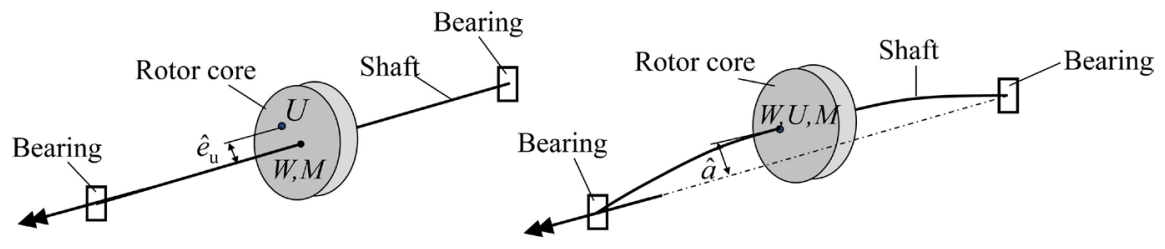

a) Eccentricity of rotor mass

b) Bent rotor deflection

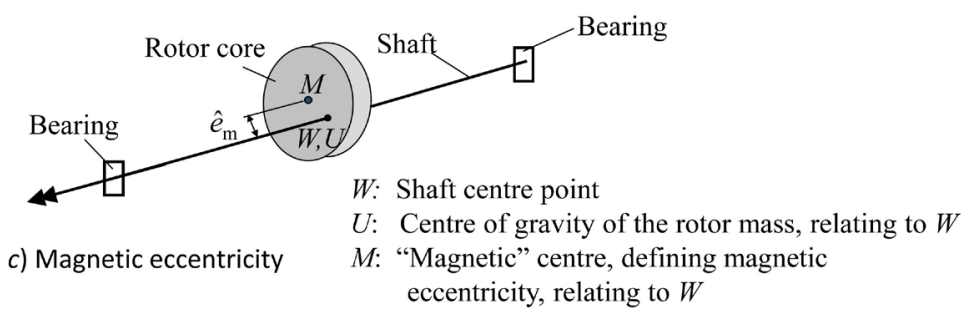

Figure 3. Dynamic rotor eccentricities.

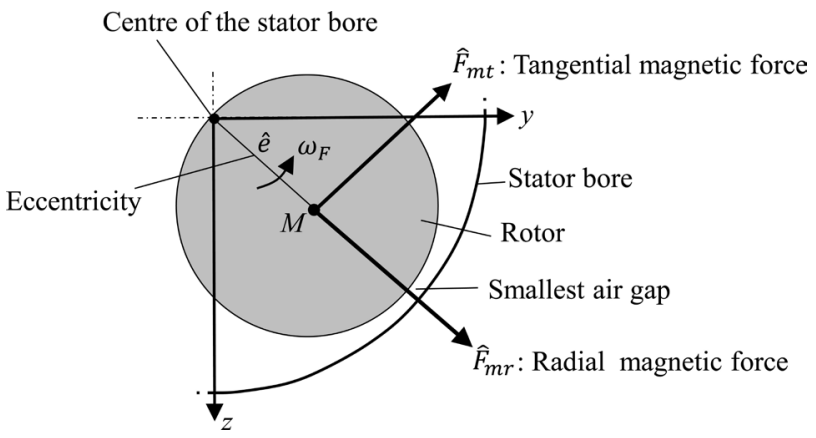

Figure 4. Magnetic forces at the rotor due to eccentricity.

- Bent rotor deflection $\hat{a}$, which is e.g. caused by thermal bending of the rotor.

- Magnetic eccentricity $\hat{e}_{m}$, which is e.g. caused by deviation of concentricity between the inner diameter of the rotor core and the outer diameter of the rotor core. The so caused mechanical unbalance is compensated by a placed unbalance, so that the centre of rotor mass $U$ is not displaced from the rotation axis.

\section{Electromagnetic Field Damping}

If the magnetic centre $M$ of the rotor is displaced from the centre of the stator bore (Figure 4), additionally electromagnetic fields-eccentricity fields-occur [4]-[9]. These additional fields produce a radial magnetic force $\hat{F}_{m r}$ in direction of the smallest air gap. If the rotor angular frequency differs to the angular frequencies of these eccentricity fields, these fields induce a voltage into the rotor cage. The so produced harmonic rotor currents create electromagnetic fields, which lower the magnitude of the origin eccentricity fields. Therefore, the radial magnetic force $\hat{F}_{m r}$ is reduced and an additional magnetic force $\hat{F}_{m t}$ is generated, in tangential direction [7] [8] [9].

These electromagnetic forces act on the rotor but in opposite direction also at the stator. For forced vibration caused by dynamic rotor eccentricity the whirl- 
ing angular frequency $\omega_{F}$ is equal to the rotational angular frequency $\Omega$ :

$$
\omega_{F}=\Omega
$$

Referring to [7] [8] [9], the radial electromagnetic force can be described by an electromagnetic spring constant $c_{m d}$ and the tangential electromagnetic force by an electromagnetic damper constant $d_{m}$ (with $\omega_{F} \neq 0$ ), depending on the pole-pair number $p$ :

$$
\begin{aligned}
& p>1:\left\{\begin{array}{l}
c_{m d}=\frac{c_{m}}{2} \cdot\left(\alpha_{p+1}+\alpha_{p-1}\right) \\
d_{m}=-\frac{1}{\omega_{F}} \cdot \frac{c_{m}}{2} \cdot\left(\delta_{p+1}-\delta_{p-1}\right) \\
\text { with }: c_{m}=\frac{\pi \cdot R \cdot l}{2 \cdot \mu_{0} \cdot \delta^{\prime \prime}} \cdot \hat{B}_{p}^{2}
\end{array}\right. \\
& p=1:\left\{\begin{array}{l}
c_{m d}=c_{m} \cdot \alpha_{p+1} \\
d_{m}=-\frac{1}{\omega_{F}} \cdot c_{m} \cdot \delta_{p+1} \\
\text { with }: c_{m}=\frac{1}{2} \cdot \frac{\pi \cdot R \cdot l}{2 \cdot \mu_{0} \cdot \delta^{\prime \prime}} \cdot \hat{B}_{p}^{2}
\end{array}\right.
\end{aligned}
$$

The constant $c_{m}$ describes the magnetic spring constant, without electromagnetic field damping, $l$ the length of the core, $R$ the radius of the stator bore, $\mu_{0}$ the permeability of air, $\delta^{\prime \prime}$ the equivalent magnetic air gap width, $\hat{B}_{p}$ the amplitude of fundamental air gap field, $\alpha_{p+1}$ and $\alpha_{p-1}$ the real parts and $\delta_{p+1}$ and $\delta_{p-1}$ the imaginary parts of the complex field damping value. For 2-pole motors $(p=1)$ the components $\alpha_{p-1}$ and $\delta_{p-1}$ do not exist, neglecting the homopolar flux. Without electromagnetic field damping, the field damping coefficients become [7] [8] [9]:

$$
\alpha_{p+1}=\alpha_{p-1}=1 ; \delta_{p+1}=\delta_{p-1}=0
$$

With the ordinal number $v=p \pm 1$ for an eccentricity field wave, the electromagnetic field damping coefficients can be calculated as follows [7] [8] [9]:

$$
\begin{aligned}
& \alpha_{v}=1-K_{v} \cdot s_{v}^{2} ; \delta_{v}=-K_{v} \cdot \beta_{v} \cdot s_{v} \text { with: } \\
& \beta_{v}=\frac{R_{2, v}}{\omega_{1}\left(L_{2 h, v}+L_{2 \sigma, v}\right)} ; K_{v}=\frac{1}{\beta_{v}^{2}+s_{v}^{2}} \cdot \frac{\xi_{\mathrm{Schr}, v}^{2} \cdot \zeta_{K, v}^{2}}{1+\frac{L_{2 \sigma, v}}{L_{2 h, v}}}
\end{aligned}
$$

$R_{2, v}$ presents the resistance of a rotor bar and ring segment, $\omega_{1}$ the electrical stator angular frequency, $L_{2 h, v}$ the main field inductance of a rotor mesh, $L_{2 \sigma, v}$ the leakage inductance of a bar and ring segment, $\xi_{\mathrm{Schr}, v}$ the screwing factor and $\zeta_{K, v}$ the coupling factor. A very important parameter is here the harmonic slip $s_{v}$, which can be described by [7] [8] [9]:

$$
s_{v}=\frac{\frac{\omega_{v}}{v}-\Omega}{\frac{\omega_{1}}{v}} \text { with : } \Omega=\frac{\omega_{1}}{p}(1-s)
$$


Here, $s$ presents the fundamental slip of the induction motor, $\omega_{1}$ the electrical stator angular frequency and $\omega_{v} / v$ the angular frequencies of the eccentricity fields, depending on the kind of eccentricity:

- Static eccentricity: $\omega_{v}=\omega_{1}$,

- Dynamic eccentricity as a circular forward whirl: $\omega_{v}=\omega_{1} \pm \omega_{F}$,

- Dynamic eccentricity as a circular backward whirl: $\omega_{v}=\omega_{1} \mp \omega_{F}$.

In order to consider electromagnetic field damping by a simple magnetic spring element $c_{m d}$ and a simple magnetic damper element $d_{m}$, the determination has to be made, that the calculation of $c_{m d}$ and $d_{m}$ is here only based on circular forward orbits [9]. This definition presents the highest electromagnetic influence, when considering electromagnetic field damping. Because of the fact, that for forced vibrations due to dynamic eccentricity the whirling frequency is equal to the rotary angular frequency $\left(\omega_{F}=\Omega\right)$, and that only circular forward orbits are considered for calculating the magnetic spring and damper value, the harmonic slip $s_{v}$ becomes equal to the fundamental slip $s$ [7] [8] [9]:

$$
s_{v}=s
$$

\section{Multibody Model}

The vibration model is on the one side an enhancement of the model in [9], where only the rotor dynamic for rigid foundation is analyzed and on the other side an enhancement of the model in [10], where no electromagnetic field damping, no rotating damping of the rotor, no damping of the bearing housing and no mass of the bearing housings and shaft journals is considered. The innovation of the presented model is now that all these influences are now united in one single multibody model. The model is a plane multibody model, which consists of two main masses, the rotor mass $m_{w}$, and the stator mass $m_{s}$, which has the inertia $\theta_{s x}$ and is concentrated in the centre of gravity $S$ (Figure 5).

Additional masses are the mass of the shaft journal $m_{v}$ and the mass of the bearing housing $m_{b}$. The rotor, rotating with the rotary angular frequency $\Omega$, presents a concentrated mass and has no inertia moments (no gyroscopic effect is considered).The movement of the shaft journal in the sleeve bearing is described by the shaft journal centre point $V$. The point $B$, which is positioned in the axial middle of the sleeve bearing shell, describes the movement of the bearing housing. The rotor mass is linked to the stator mass by the stiffness $c$ and internal (rotating) damping $d_{i}$ of the rotor, the oil film stiffness matrix $C_{v}$ and oil film damping matrix $D_{v}$ of the sleeve bearings, which suppose to be equal for both sides, as well as the bearing house and end shield stiffness and damping matrix $C_{b}$ and $D_{b}$. The stator structure can be defined to be rigid, compared to the soft foundation. The foundation stiffness matrix $C_{f}$ and the foundation damping matrix $D_{f}$ connect the stator feet, $F_{L}$ (left side) and $F_{R}$ (right side), to the ground. The foundation stiffness and damping on the right side and on the left side is identical and the foundation stiffness values $c_{f y}$ and $c_{f z}$ and the foundation damping values $d_{f y}$ and $d_{f z}$ are the values for each motor side. 


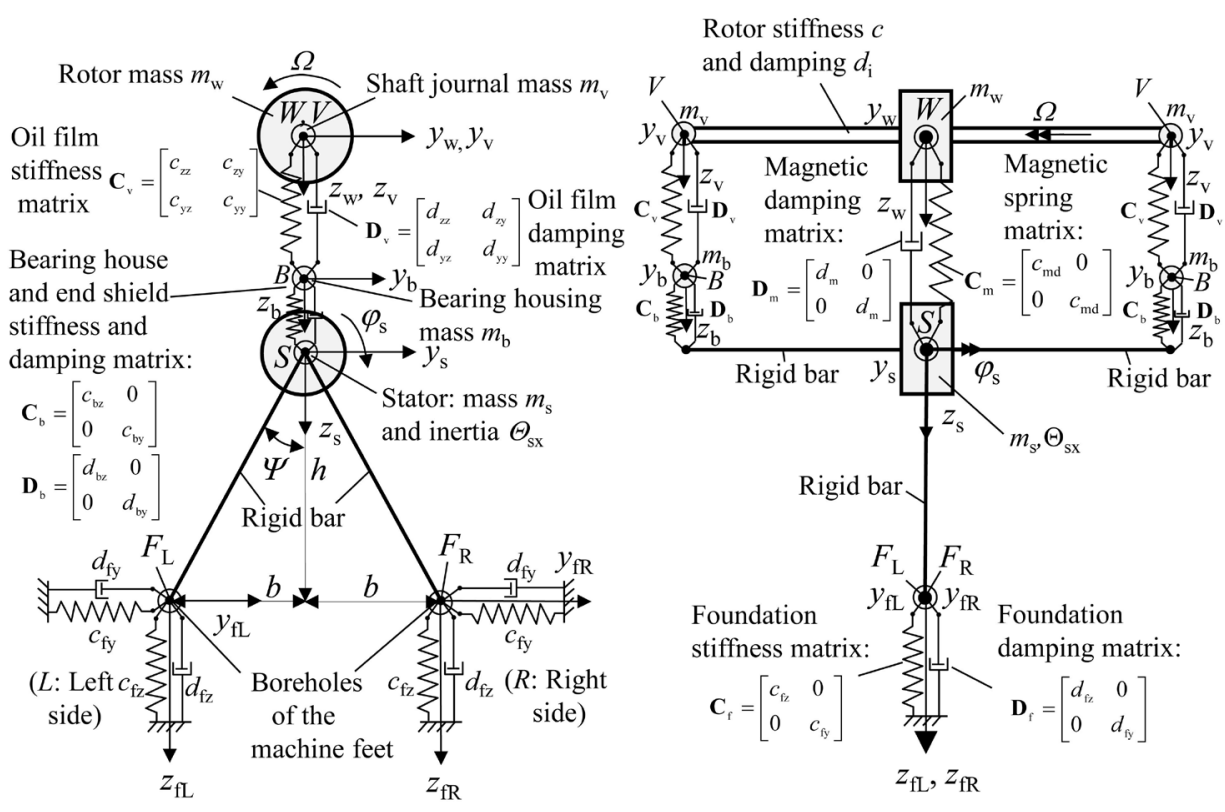

(a) View from $x$-direction Note: Magnetic spring and damper

(b) View from y-direction

Figure 5. Multibody model.

The electromagnetism is considered by the electromagnetic spring and damper matrix $\boldsymbol{C}_{m}$ and $\boldsymbol{D}_{m}$, where also electromagnetic field damping is included. Excitations are all three kinds of dynamic rotor eccentricity-eccentricity of rotor mass, bent rotor deflection and magnetic eccentricity-but are not pictured in Figure 5, because of the complexity. All used coordinate systems are fixed.

\section{Stiffness and Damping Coefficients}

The oil film stiffness and damping coefficients $c_{i j}$ and $d_{i j}(i, j=z, y)$ of the sleeve bearing can be calculated by solving the Reynolds differential equation [15] [16], and are depending on the rotary angular frequency $\Omega$ :

$$
c_{i j}=c_{i j}(\Omega) ; \quad d_{i j}=d_{i j}(\Omega)
$$

The stiffness of the rotor $c$ is constant. According to [3], the internal material damping of the rotor $d_{i}$ is described here by the mechanical loss factor $\tan \delta_{i}$ of the rotor, depending on the whirling angular frequency $\omega_{F}$, which is here identically to the rotary angular frequency $\Omega$ :

$$
d_{i}(\Omega)=\frac{c \cdot \tan \delta_{i}}{\Omega}
$$

The same approach is used for the bearing housing with end shield and the foundation. The stiffness of the bearing housing with end shield $\left(c_{b z} ; c_{b y}\right)$ and of the foundation $\left(c_{f_{z}} ; c_{f y}\right)$ is constant. The damping of the bearing housing with end shield $\left(d_{b z} ; d_{b y}\right)$ and of the foundation $\left(d_{f z} ; d_{f y}\right)$ can be again described by the mechanical loss factor of the bearing housing with end shield $\tan \delta_{b}$ and of the foundation $\tan \delta_{f}$ :

$$
d_{b z}(\Omega)=\frac{c_{b z} \cdot \tan \delta_{b}}{\Omega} ; \quad d_{b y}(\Omega)=\frac{c_{b y} \cdot \tan \delta_{b}}{\Omega}
$$




$$
d_{f z}(\Omega)=\frac{c_{f z} \cdot \tan \delta_{f}}{\Omega} ; \quad d_{f y}(\Omega)=\frac{c_{f y} \cdot \tan \delta_{f}}{\Omega}
$$

The electromagnetic stiffness coefficient $c_{m d}$ and damping coefficient $d_{m}$ are depending on the harmonic slip $s_{v}$, which is here equal to the fundament slip $s$, and on the whirling angular frequency $\omega_{F}$, which is here equal to the rotary angular frequency $\Omega$. If the motor is converter driven, the angular rotor frequency $\Omega$ as well as the fundament slip $s$ may variate arbitrarily. Therefore $c_{m d}$ and $d_{m}$ become:

$$
c_{m d}=c_{m d}(\Omega, s) ; \quad d_{m}=d_{m}(\Omega, s)
$$

\section{Mathematical Description}

\subsection{Derivation of the Differential Equation System}

The forces at the rotor mass, at the shaft journals, at the bearing housings and at the stator mass can be derived in the fixed coordinate systems $\left(y_{W}, z_{W} ; y_{V}, z_{V} ; y_{B}, z_{B} ; y_{S}, z_{S}\right)$ (Figure 6). The rotating coordinate system $\left(y_{r w}, z_{r w}\right)$ in Figure 6(a) is used for transferring the rotating damping of the rotor shaft from the rotating coordinate system into the fixed coordinate system $\left(y_{W}, z_{W}\right)$ [9]. The fixed coordinate systems in Figures 6(a)-(d) are used for

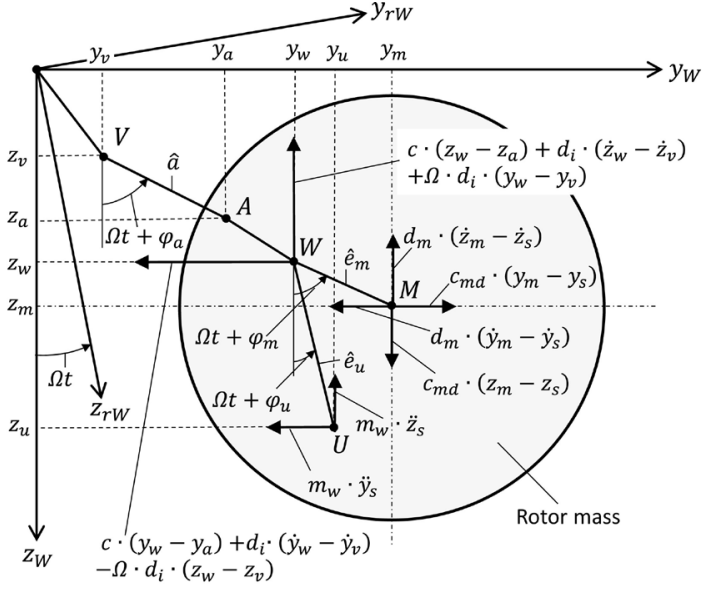

(a) Rotor mass system

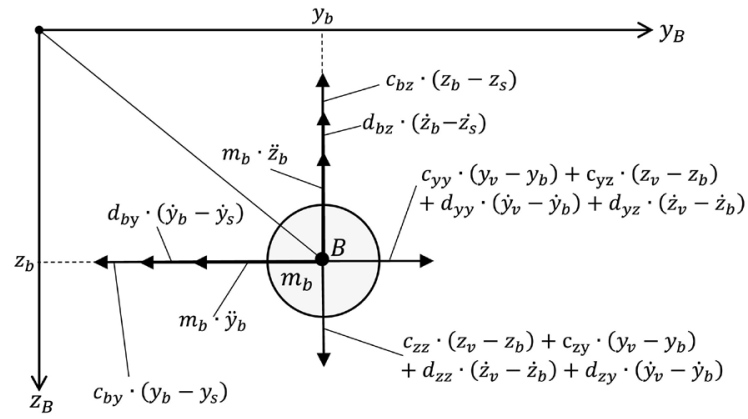

(c) Bearing house system

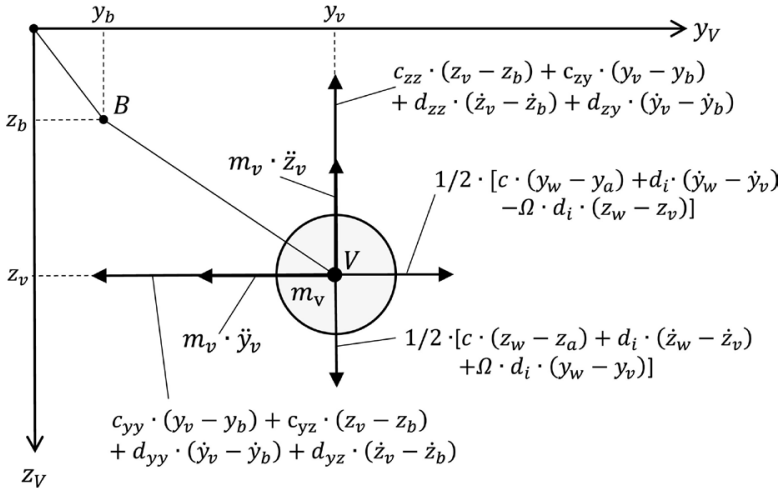

(b) Journal system

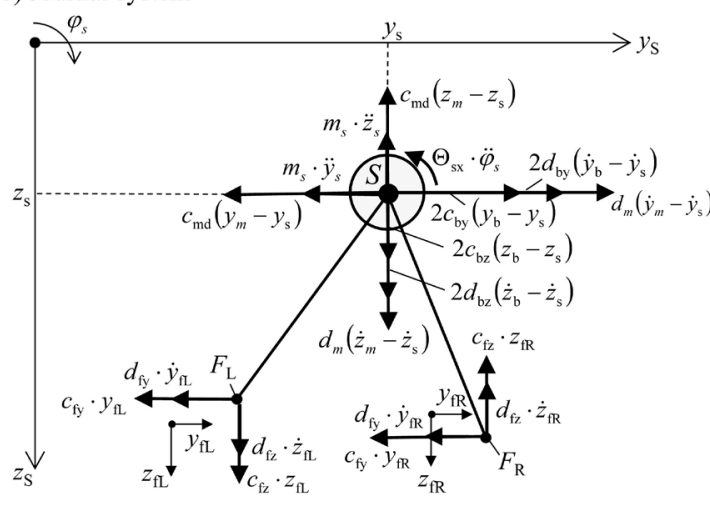

Note: The negative vertical displacement in $F_{L}$, relating to the coordinate $z_{f L}$, is considered by the direction of the vertical forces in $F_{L}$, so $z_{f L}$ has to be described in the differential equation by: $z_{f L}=-z_{s}+\varphi_{s} \cdot b$

(d) Stator mass system

Figure 6. Vibration system split into subsystems. 
deriving the equilibrium of forces and moments, for each single system.

Because of the small displacements of the stator mass $\left(z_{s}, y_{s}, \varphi_{s}\right)$ related to the dimensions of the machine $(h, b, \Psi)$, linearization is possible [10]:

$$
\begin{gathered}
z_{f L}=z_{s}-\varphi_{s} \cdot b ; z_{f R}=z_{s}+\varphi_{s} \cdot b \\
y_{f L}=y_{f R}=y_{s}-\varphi_{s} \cdot h
\end{gathered}
$$

To derive the inhomogeneous differential equation system, each single system -Figures 6(a)-(d)-has to be analyzed. In Figures 6(a)-(c) the equilibrium of forces in vertical direction ( $z$-direction) and in horizontal direction( $y$-direction) has to be determined for each single system. In Figure 6(d) additionally to the equilibrium of forces, the equilibrium of moments at the point $S$ has to be determined. Based on these 9 differential equations, following inhomogeneous differential equation system can be derived:

$$
\boldsymbol{M} \cdot \ddot{\boldsymbol{q}}+\boldsymbol{D} \cdot \dot{\boldsymbol{q}}+\boldsymbol{C} \cdot \boldsymbol{q}=\boldsymbol{f}_{u}+\boldsymbol{f}_{a}+\boldsymbol{f}_{m}
$$

Coordinate vector $\boldsymbol{q}$ :

$$
\boldsymbol{q}=\left[z_{s} ; z_{w} ; y_{s} ; y_{w} ; \varphi_{s} ; z_{v} ; z_{b} ; y_{v} ; y_{b}\right]^{\mathrm{T}}
$$

Mass matrix $\boldsymbol{M}$ :

$$
\boldsymbol{M}=\left[\begin{array}{ccccccccc}
m_{s} & 0 & 0 & 0 & 0 & 0 & 0 & 0 & 0 \\
0 & m_{w} & 0 & 0 & 0 & 0 & 0 & 0 & 0 \\
0 & 0 & m_{s} & 0 & 0 & 0 & 0 & 0 & 0 \\
0 & 0 & 0 & m_{w} & 0 & 0 & 0 & 0 & 0 \\
0 & 0 & 0 & 0 & \Theta_{s x} & 0 & 0 & 0 & 0 \\
0 & 0 & 0 & 0 & 0 & 2 m_{v} & 0 & 0 & 0 \\
0 & 0 & 0 & 0 & 0 & 0 & 2 m_{b} & 0 & 0 \\
0 & 0 & 0 & 0 & 0 & 0 & 0 & 2 m_{v} & 0 \\
0 & 0 & 0 & 0 & 0 & 0 & 0 & 0 & 2 m_{b}
\end{array}\right]
$$

Damping matrix $\boldsymbol{D}$ :

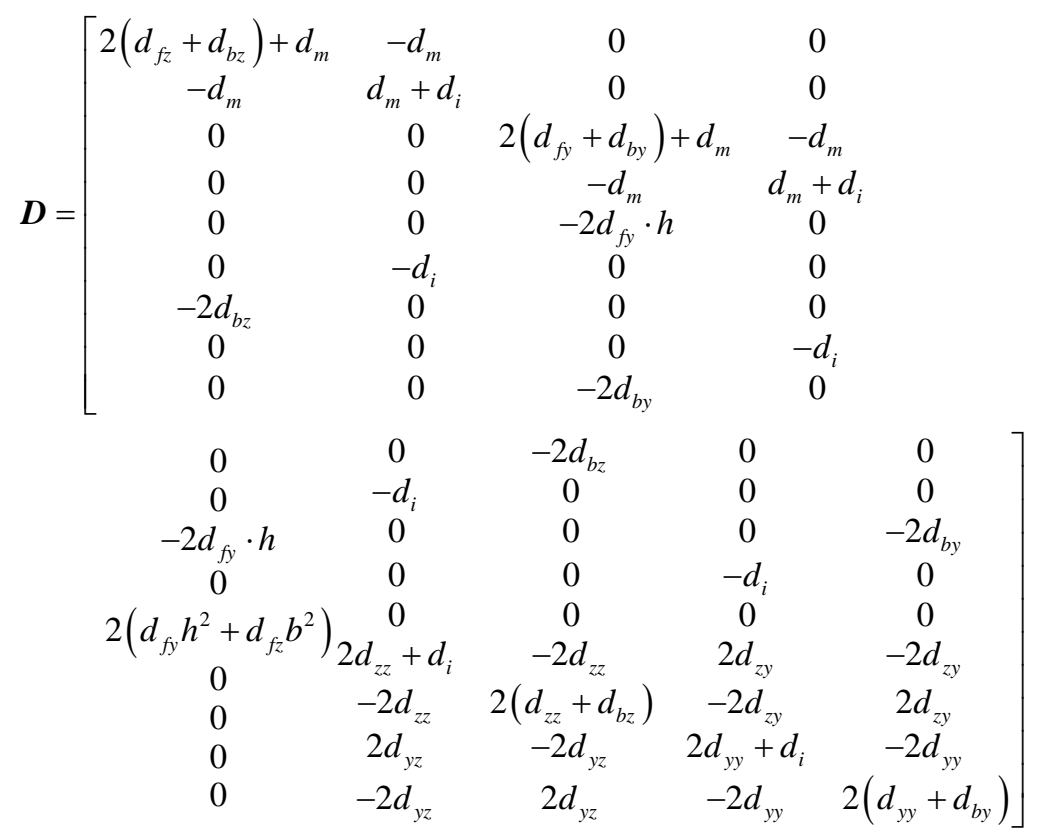


Stiffness matrix $C$ :

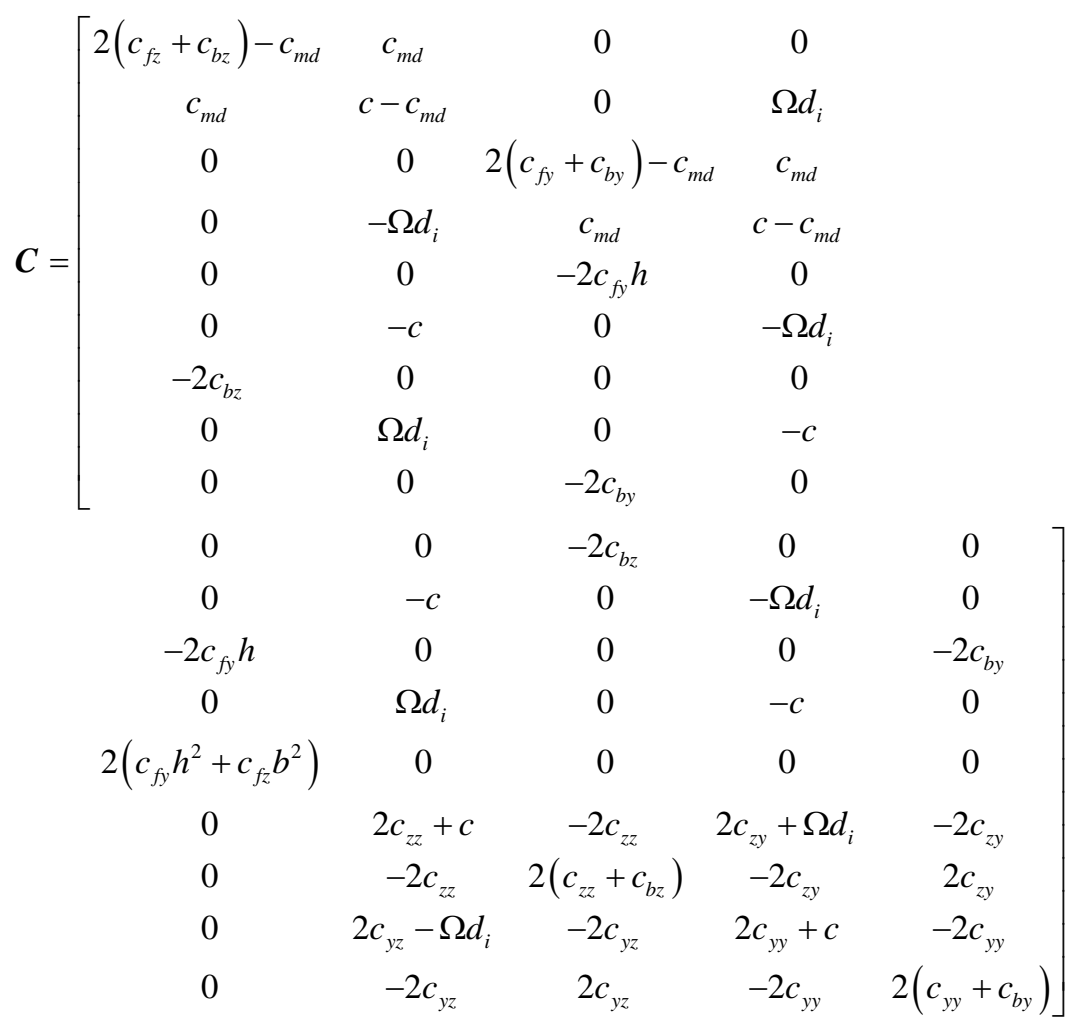

For the calculation of the forced vibrations, the complex form is used. Therefore the excitation vectors can be described as follows:

- Mass eccentricity:

$$
\boldsymbol{f}_{u}=\hat{\boldsymbol{f}}_{u} \cdot \mathrm{e}^{j \cdot\left(\Omega \cdot t+\varphi_{u}\right)}
$$

- Bent rotor deflection:

$$
\boldsymbol{f}_{a}=\hat{\boldsymbol{f}}_{a} \cdot \mathrm{e}^{j \cdot\left(\Omega \cdot t+\varphi_{a}\right)}
$$

- Magnetic eccentricity

$$
\boldsymbol{f}_{m}=\hat{\boldsymbol{f}}_{m} \cdot \mathrm{e}^{j \cdot\left(\Omega \cdot t+\varphi_{m}\right)}
$$

with the amplitude vectors:

$$
\hat{\boldsymbol{f}}_{u}=\left[\begin{array}{c}
0 \\
\hat{e}_{u} \cdot m_{w} \cdot \Omega^{2} \\
0 \\
-j \cdot \hat{e}_{u} \cdot m_{w} \cdot \Omega^{2} \\
0 \\
0 \\
0 \\
0 \\
0
\end{array}\right] ; \hat{\boldsymbol{f}}_{a}=\left[\begin{array}{c}
0 \\
\hat{a} \cdot c \\
0 \\
-j \cdot \hat{a} \cdot c \\
0 \\
-\hat{a} \cdot c \\
0 \\
j \cdot \hat{a} \cdot c \\
0
\end{array}\right] ; \hat{\boldsymbol{f}}_{m}=\left[\begin{array}{c}
-\hat{e}_{m} \cdot c_{m d} \\
\hat{e}_{m} \cdot c_{m d} \\
j \cdot \hat{e}_{m} \cdot c_{m d} \\
-j \cdot \hat{e}_{m} \cdot c_{m d} \\
0 \\
0 \\
0 \\
0 \\
0
\end{array}\right]
$$

\subsection{Solution of the Differential Equation System}

With the complex form for each particular excitation: 


$$
\boldsymbol{q}_{\kappa}=\hat{\boldsymbol{q}}_{\kappa} \cdot \mathrm{e}^{j \cdot\left(\Omega t+\varphi_{\kappa}\right)} ; \kappa=u, a, m
$$

the complex amplitude vector for each single excitation can be calculated by:

$$
\begin{aligned}
& \hat{\boldsymbol{q}}_{\kappa}=\left[-\boldsymbol{M} \cdot \Omega^{2}+\boldsymbol{D} \cdot j \cdot \Omega+\boldsymbol{C}\right]^{-1} \cdot \hat{\boldsymbol{f}}_{\kappa} ; \text { with: } \\
& \hat{\boldsymbol{q}}_{\kappa}=\left[\begin{array}{l}
\hat{z}_{s, \kappa} \\
\hat{z}_{w, \kappa} \\
\hat{y}_{s, \kappa} \\
\hat{y}_{w, \kappa} \\
\hat{\varphi}_{s, \kappa} \\
\hat{z}_{v, \kappa} \\
\hat{z}_{b, \kappa} \\
\hat{y}_{v, \kappa} \\
\hat{y}_{b, \kappa}
\end{array}\right]=\left[\begin{array}{l}
\left|\hat{z}_{s, \kappa}\right| \cdot \mathrm{e}^{j \cdot \alpha_{z_{s, \kappa}}} \\
\left|\hat{z}_{w, \kappa}\right| \cdot \mathrm{e}^{j \cdot \alpha_{z_{w, \kappa}}} \\
\left|\hat{y}_{s, \kappa}\right| \cdot \mathrm{e}^{j \cdot \alpha_{y_{s, \kappa}}} \\
\left|\hat{y}_{w, \kappa}\right| \cdot \mathrm{e}^{j \cdot \alpha_{y_{w, \kappa}}} \\
\left|\hat{\varphi}_{s, \kappa}\right| \cdot \mathrm{e}^{j \cdot \alpha_{\varphi_{s, \kappa}}} \\
\left|\hat{z}_{v, \kappa}\right| \cdot \mathrm{e}^{j \cdot \alpha_{z_{v, \kappa}}} \\
\left|\hat{z}_{b, \kappa}\right| \cdot \mathrm{e}^{j \cdot \alpha_{z_{b, \kappa}}} \\
\left|\hat{y}_{v, \kappa}\right| \cdot \mathrm{e}^{j \cdot \alpha_{v_{v, \kappa}}} \\
\left|\hat{y}_{b, \kappa}\right| \cdot \mathrm{e}^{j \cdot \alpha_{y_{b, \kappa}}}
\end{array}\right] ; \kappa=u, a, m
\end{aligned}
$$

and each single solution can now be described by:

$$
\boldsymbol{q}_{u}=\hat{\boldsymbol{q}}_{u} \cdot \mathrm{e}^{j\left(\Omega t+\varphi_{u}\right)} ; \boldsymbol{q}_{m}=\hat{\boldsymbol{q}}_{m} \cdot \mathrm{e}^{j\left(\Omega t+\varphi_{m}\right)} ; \boldsymbol{q}_{a}=\hat{\boldsymbol{q}}_{a} \cdot \mathrm{e}^{j\left(\Omega t+\varphi_{a}\right)}
$$

Afterwards, all single solutions can be superposed:

$$
\boldsymbol{q}=\sum_{\kappa=u, a, m} \hat{\boldsymbol{q}}_{\kappa} \cdot \mathrm{e}^{j\left(\Omega t+\varphi_{\kappa}\right)}
$$

\subsection{Sleeve Bearing Housing Vibrations}

Now, the vibration velocities of the bearing housings can be calculated for each single excitation [9]:

$$
\begin{gathered}
\text { Vertical direction }: v_{b, z, \kappa}=\Omega \cdot\left|\hat{z}_{b, \kappa}\right| \\
\text { Horizontal direction: } v_{b, y, \kappa}=\Omega \cdot\left|\hat{y}_{b, \kappa}\right|
\end{gathered}
$$

Again, the solutions can be superposed:

Vertical direction:

$$
v_{b, z}=\Omega \cdot\left|\sum_{\kappa=u, a, m}\right| \hat{z}_{b, \kappa}\left|\cdot e^{j\left(\varphi_{\kappa}+\alpha_{z_{b, \kappa}}\right)}\right|
$$

Horizontal direction:

$$
v_{b, y}=\Omega \cdot\left|\sum_{\kappa=u, a, m}\right| \hat{y}_{b, \kappa}\left|\cdot e^{j\left(\varphi_{\kappa}+\alpha_{y_{b, \kappa}}\right)}\right|
$$

\subsection{Relative Shaft Displacements}

Referring to [9], the complex vector, describing the relative orbit between the bearing housing point $B$ and the shaft journal point $V$ can now be calculated as follows: 
$\underline{r}_{-b, \kappa}=\underline{\hat{r}}_{-b, \kappa}^{+} \cdot \mathrm{e}^{j \cdot\left(\Omega t+\varphi_{\kappa}\right)}+\underline{\hat{r}}_{-b, \kappa}^{-} \cdot \mathrm{e}^{-j \cdot\left(\Omega t+\varphi_{K}\right)}$

with :

$$
\begin{aligned}
\underline{\hat{r}}_{-b, \kappa}^{+} & =\frac{1}{2} \cdot\left\{\left|\hat{z}_{v, \kappa}\right| \cdot \mathrm{e}^{j \cdot \alpha_{z_{v, \kappa}}}-\left|\hat{z}_{b, \kappa}\right| \cdot \mathrm{e}^{j \cdot \alpha_{z_{b, \kappa}}}+j \cdot\left[\left|\hat{y}_{v, \kappa}\right| \cdot \mathrm{e}^{j \cdot \alpha_{y_{v, \kappa}}}-\left|\hat{y}_{b, \kappa}\right| \cdot \mathrm{e}^{j \cdot \alpha_{y_{b, \kappa}}}\right]\right\}= \\
& =\left|\hat{\underline{r}}_{-b, \kappa}^{+}\right| \cdot \mathrm{e}^{j \cdot \alpha_{v-b, \kappa}^{+}} \\
\underline{\hat{r}}_{-b, \kappa}^{-} & =\frac{1}{2} \cdot\left\{\left|\hat{z}_{v, \kappa}\right| \cdot \mathrm{e}^{-j \cdot \alpha_{z_{v, \kappa}}}-\left|\hat{z}_{b, \kappa}\right| \cdot \mathrm{e}^{-j \cdot \alpha_{z_{b, \kappa}}}+j \cdot\left[\left|\hat{y}_{v, \kappa}\right| \cdot \mathrm{e}^{-j \cdot \alpha_{y_{v, \kappa}}}-\left|\hat{y}_{b, \kappa}\right| \cdot \mathrm{e}^{-j \cdot \alpha_{y_{b, \kappa}}}\right]\right\}= \\
& =\left|\hat{\underline{r}}_{-b, \kappa}^{-}\right| \cdot \mathrm{e}^{j \cdot \alpha_{v-b, \kappa}^{-}}
\end{aligned}
$$

where $\hat{r}_{--b, \kappa}^{+}$and $\alpha_{v-b, \kappa}^{+}$describe the absolute value and the phase shift of the forward rotating complex pointer and $\left|\hat{\hat{r}}_{-b, \kappa}^{-}\right|$and $\alpha_{v-b, \kappa}^{-}$the absolute value and the phase shift of the backward rotating complex pointer.

The relative orbit between the shaft journal point $V$ and of the bearing housing $B$ can also be described by the ellipse parameters-semi-major axis $a_{v-b, \kappa}$, the semi-minor axis $b_{v-b, \kappa}$ and the angle of the relative major axis $\psi_{v-b, \kappa}$ related to the vertical axis (z-direction) - can be calculated:

$$
\begin{gathered}
a_{v-b, \kappa}=\left|\hat{\hat{r}}_{-b, \kappa}^{+}\right|+\left|\hat{\underline{r}}_{--b, \kappa}^{-}\right| \\
b_{v-b, \kappa}=|| \hat{\underline{r}}_{u-b, \kappa}^{+}|-| \hat{\underline{r}}_{-b, \kappa}^{-}|| \\
\psi_{v-b, \kappa}=\left(\alpha_{v-b, \kappa}^{+}+\alpha_{v-b, \kappa}^{-}\right) / 2
\end{gathered}
$$

Again the single solutions can be superposed:

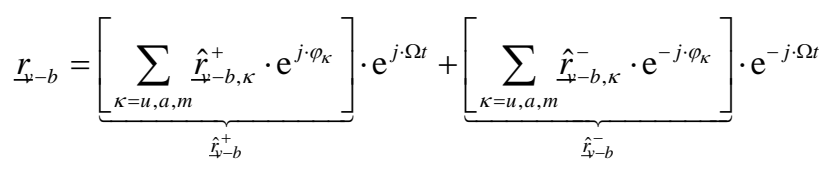

\section{Numerical Example}

In this section the bearing housing vibrations and the relative shaft displacements in the sleeve bearings of a 2-pole converter driven induction motor, mounted on a soft steel frame foundation, is analyzed. First, the boundary conditions have to be described.

\subsection{Boundary Conditions}

The data of the 2-pole induction motor and the sleeve bearings are listed in $\mathrm{Ta}$ ble 1 . The induction motor is driven in steady state condition by a converter in an operating speed range between $600 \mathrm{rpm}(\Omega=62.83 \mathrm{rad} / \mathrm{s})$ and $3800 \mathrm{rpm}$ $(\Omega=397.94 \mathrm{rad} / \mathrm{s})$ with constant magnetization.

The calculated oil film stiffness and damping coefficients of the sleeve bearings are shown in Figure 7.

The magnetic spring constant $c_{m d}$ and magnetic damper constant $d_{m}$ are calculated, depending on the rotary angular frequency $\Omega$ and on the fundamental slip $s$. The fundament slip $s$ is varying between 0 (no load operation) and 0.01 (operation near below the breaking torque) (Figure 8).

Figure 8 shows that for no-load operation $(s \sim 0)$ the magnetic spring con- 
stant $c_{m d}$ is maximal and the magnetic damping constant $d_{m}$ becomes zero. For this case, no electromagnetic field damping occurs. With increasing fundamental $s$ electromagnetic field damping occurs, and the magnetic spring constant $c_{m d}$ decreases. The magnetic damper constant $d_{m}$ reaches its maximum at a certain slip and declines, if the slip increases furthermore.

Table 1. Data of induction motor and soft steel frame foundation.

\begin{tabular}{|c|c|c|}
\hline Motor data & Description & Value \\
\hline & Rated power & $P_{n}=2400 \mathrm{~kW}$ \\
\hline & Rated speed & $n_{N}=3600 \mathrm{rpm}$ \\
\hline & Rated torque & $M_{N}=6366 \mathrm{Nm}$ \\
\hline & Rated slip & $s_{N}=0.0025$ \\
\hline & Pole-pair number & $p=1$ \\
\hline & Undamped magnetic spring constant & $c_{m}=7.0 \times 10^{6} \mathrm{~kg} / \mathrm{s}^{2}$ \\
\hline & Mass of the stator & $m_{s}=7040 \mathrm{~kg}$ \\
\hline & Mass inertia of the stator at $X$-axis & $\theta_{s x}=1550 \mathrm{kgm}^{2}$ \\
\hline & Mass of the rotor & $m_{w}=1900 \mathrm{~kg}$ \\
\hline & Mass of the rotor shaft journal & $m_{v}=10 \mathrm{~kg}$ \\
\hline & Mass of the bearing housing & $m_{b}=80 \mathrm{~kg}$ \\
\hline & Height of the centre of gravity & $h=560 \mathrm{~mm}$ \\
\hline & Distance between motor feet & $2 b=1060 \mathrm{~mm}$ \\
\hline & Stiffness of the rotor & $c=1.8 \times 10^{8} \mathrm{~kg} / \mathrm{s}^{2}$ \\
\hline & Horizontal stiffness of bearing housing and end shield & $C_{b y}=4.8 \times 10^{8} \mathrm{~kg} / \mathrm{s}^{2}$ \\
\hline & Vertical stiffness of bearing housing and end shield & $c_{b z}=5.7 \times 10^{8} \mathrm{~kg} / \mathrm{s}^{2}$ \\
\hline & Mechanical loss factor of bearing housing and end shield & $\tan \delta_{b}=0.04$ \\
\hline & Mechanical loss factor of the rotor & $\tan \delta_{i}=0.03$ \\
\hline \multirow{8}{*}{$\begin{array}{c}\text { Sleeve } \\
\text { bearing data }\end{array}$} & Description & Value \\
\hline & Bearing shell & Cylindrical \\
\hline & Lubricant viscosity grade & ISO VG 32 \\
\hline & Nominal bore diameter & $d_{b}=100 \mathrm{~mm}$ \\
\hline & Bearing width & $b_{b}=81.4 \mathrm{~mm}$ \\
\hline & Ambient temperature & $T_{a m b}=20^{\circ} \mathrm{C}$ \\
\hline & Supply oil temperature & $T_{i n}=40^{\circ} \mathrm{C}$ \\
\hline & Mean relative bearing clearance (DIN 31698) & $\Psi_{m}=1.6 \% \mathrm{o}$ \\
\hline \multirow[t]{4}{*}{$\begin{array}{c}\text { Foundation } \\
\text { data }\end{array}$} & Description & Value \\
\hline & Vertical stiffness of the foundation at each motor side & $c_{f z}=1.5 \times 10^{8} \mathrm{~kg} / \mathrm{s}^{2}$ \\
\hline & Horizontal stiffness of the foundation at each motor side & $c_{f y}=1.0 \times 10^{8} \mathrm{~kg} / \mathrm{s}^{2}$ \\
\hline & Mechanical loss factor of the foundation & $\tan \delta_{f}=0.04$ \\
\hline
\end{tabular}



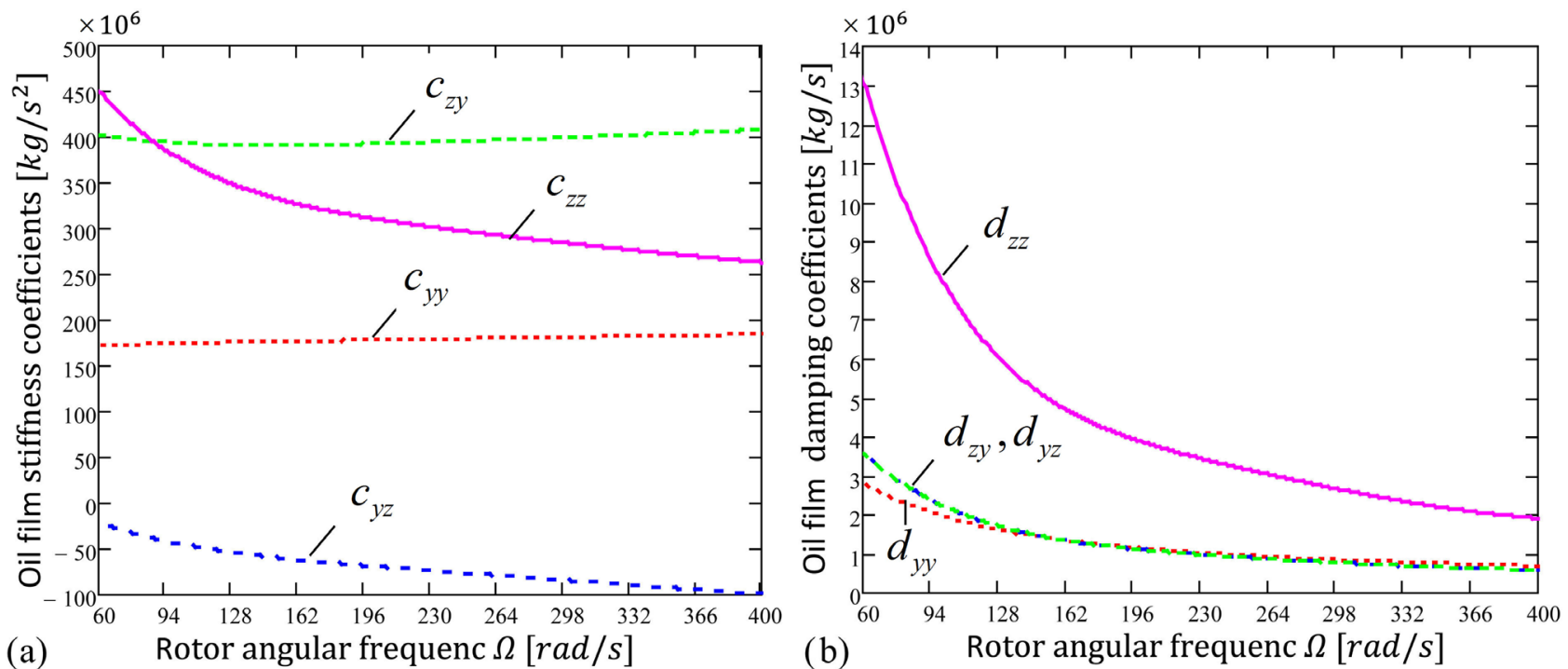

Figure 7. Oil film stiffness coefficients (a) and oil film damping coefficients (b) of the sleeve bearings.

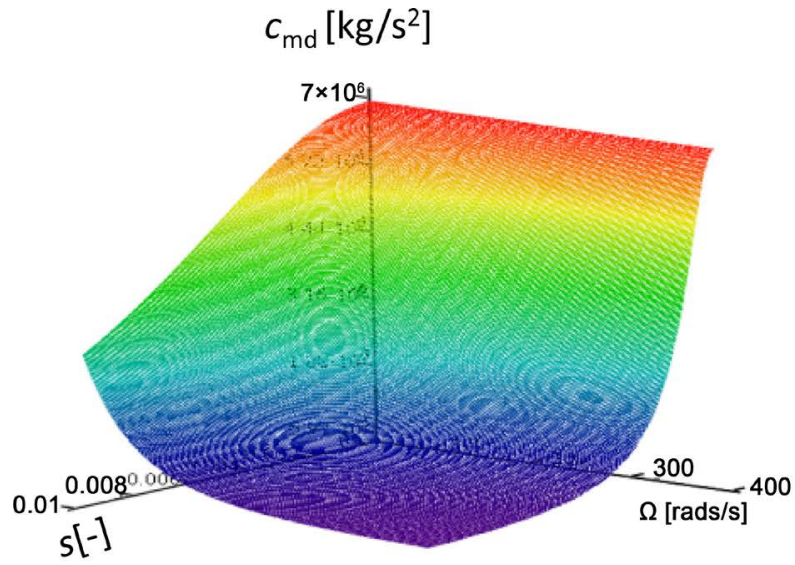

(a)

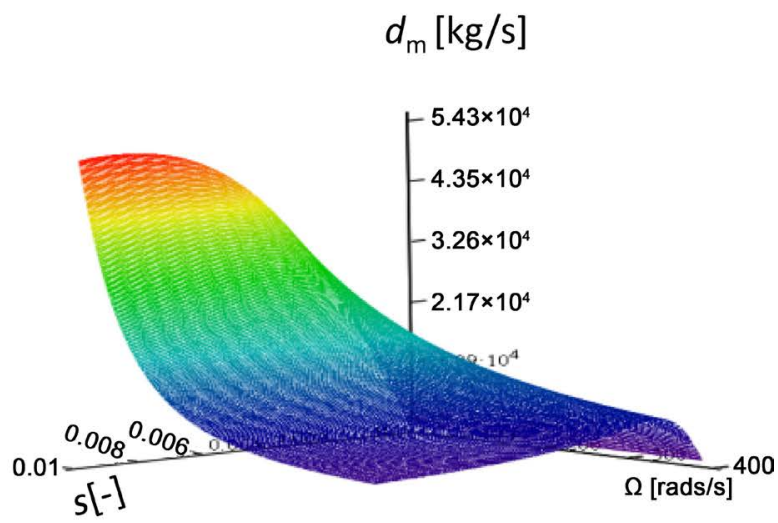

(b)

Figure 8. (a) Magnetic spring constant and (b) Magnetic damper constant; depending on fundamental slip $s$ and rotor angluar frequency $\Omega$.

\subsection{Vibrations for a Rigid Foundation}

First, the vibrations of the induction motor, mounted on a rigid foundation $\left(c_{f z}=c_{f y} \rightarrow \infty\right)$, are analyzed. The bearing housing vibration velocities and the semi-major axis of of the relative orbit between bearing housing point $B$ and shaft journal point $V$, are calculated for the different kinds of rotor eccentricity. The vibration velocities and the semi-major axes are related to the corresponding rotor eccentricity. The related bearing housing vibration velocities are shown in Figure 9.

The related semi-major axis of the relative orbit is shown in Figure 10.

\subsection{Vibrations for the Soft Foundation}

Now the vibrations are analyzed for the soft foundation $\left(c_{f z}=1.5 \times 10^{8} \mathrm{~kg} / \mathrm{s}^{2} ; c_{f y}=1.0 \times 10^{8} \mathrm{~kg} / \mathrm{s}^{2}\right)$. The related bearing housing vibration velocities are shown in Figure 11. 

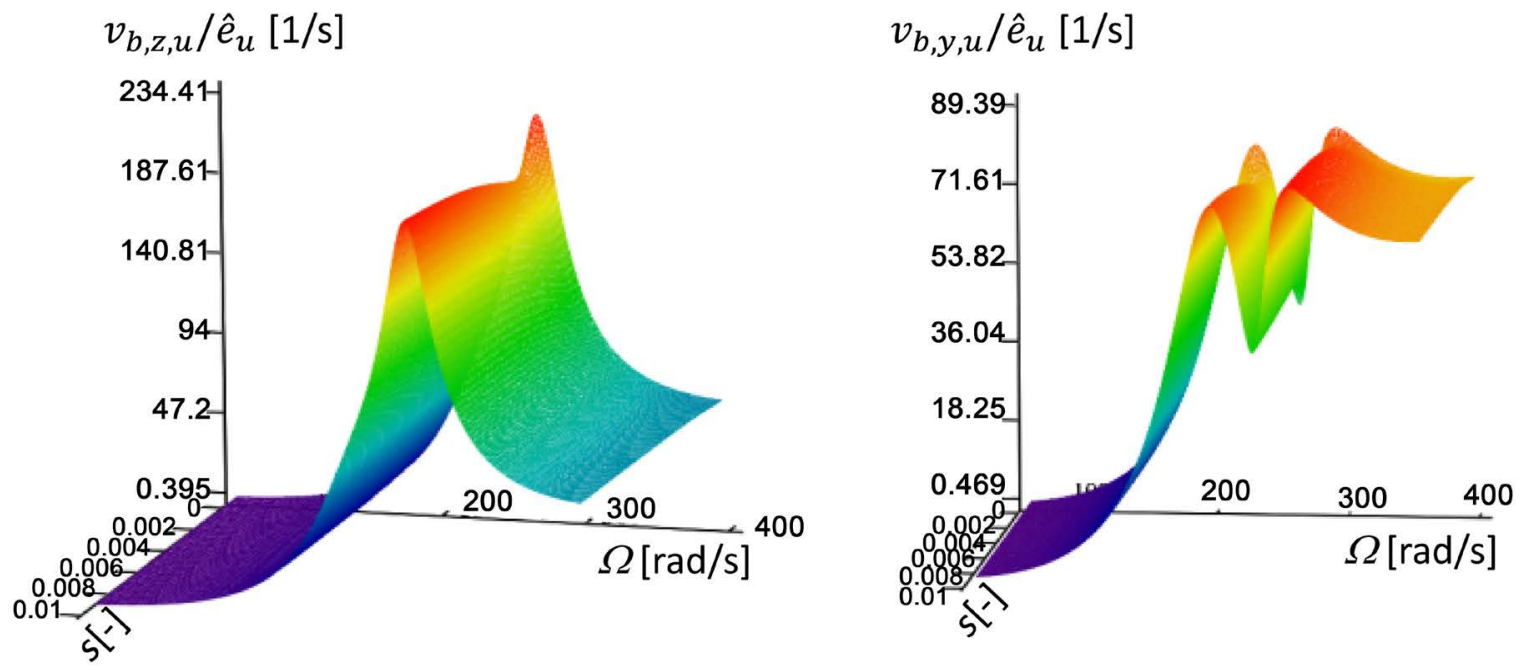

(a)
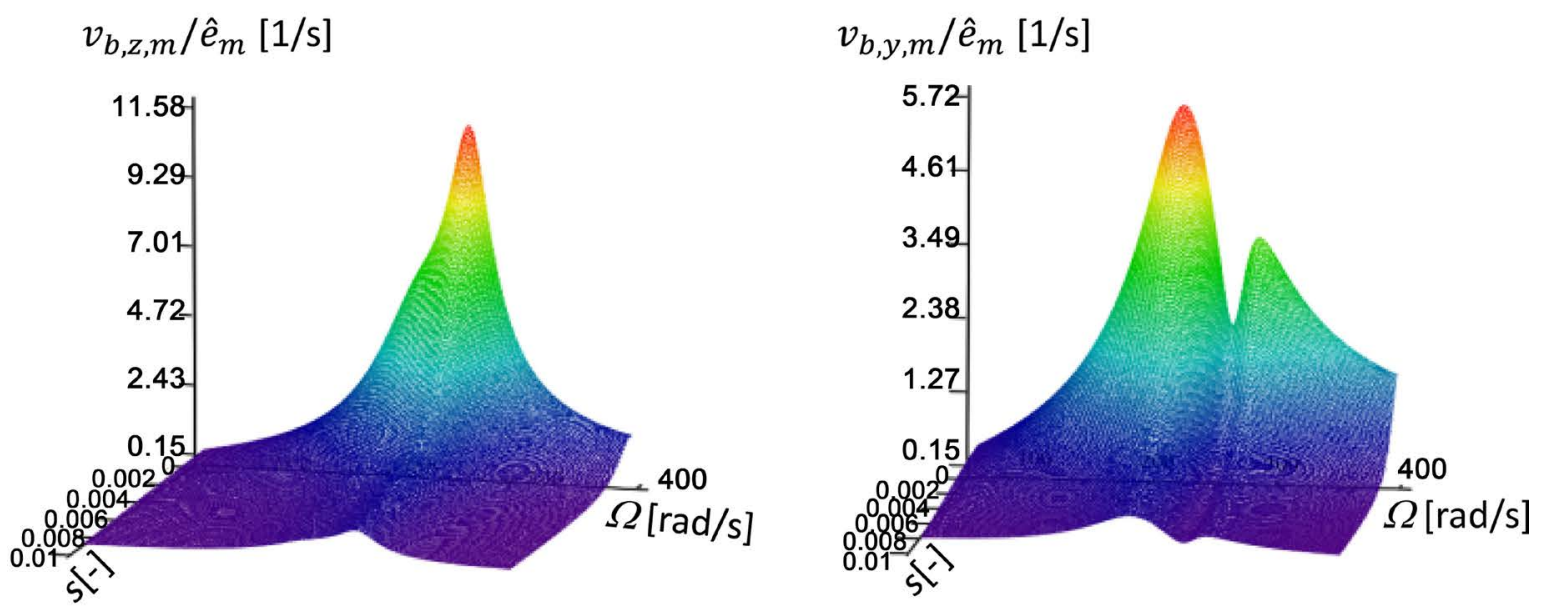

(b)

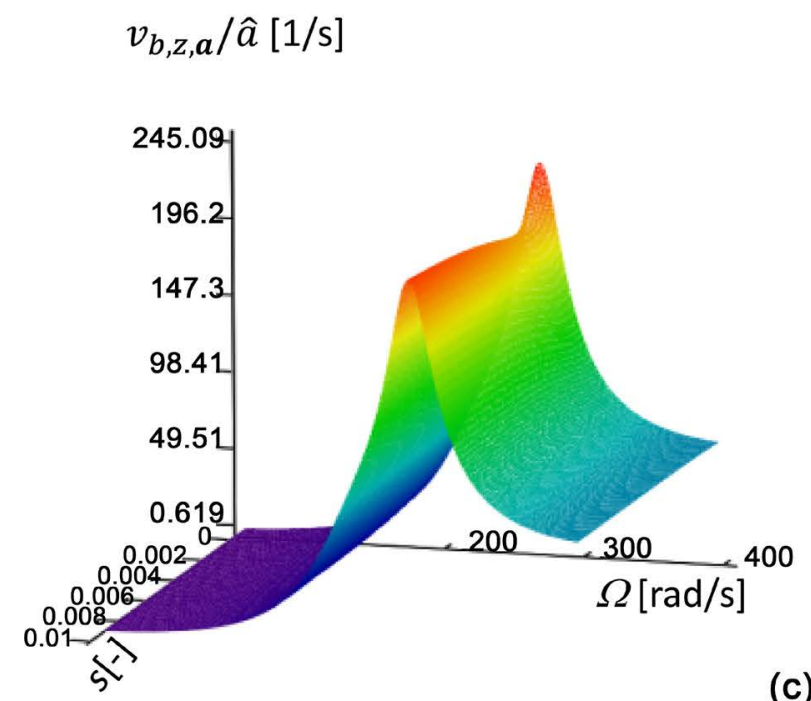

$$
v_{b, y, a} / \hat{a}[1 / s]
$$

(c)

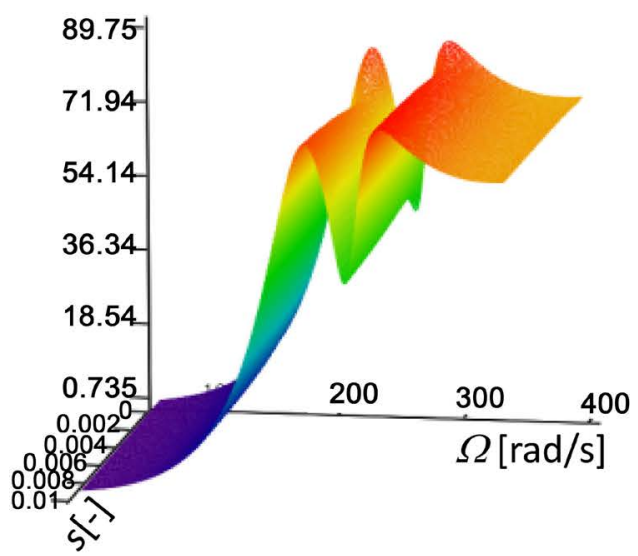

Figure 9. Related bearing housing vibration velocities for a rigid foundation- $z$-direction (left diagram) and y-direction (right diagram): (a) mass eccentricity $\hat{e}_{u}$; (b) magnetic eccentricity $\hat{e}_{m} ;$ (c) bent rotor deflection $\hat{a}$. 


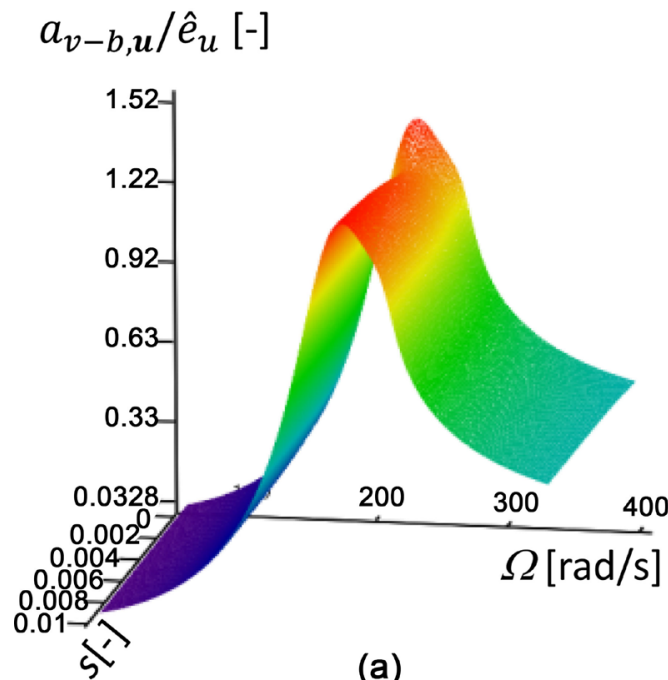

(a)

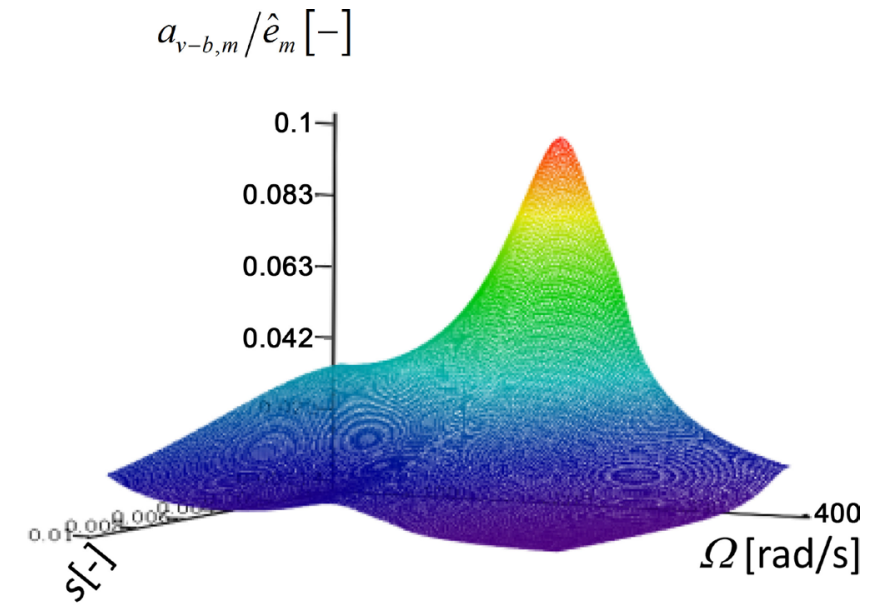

(b)

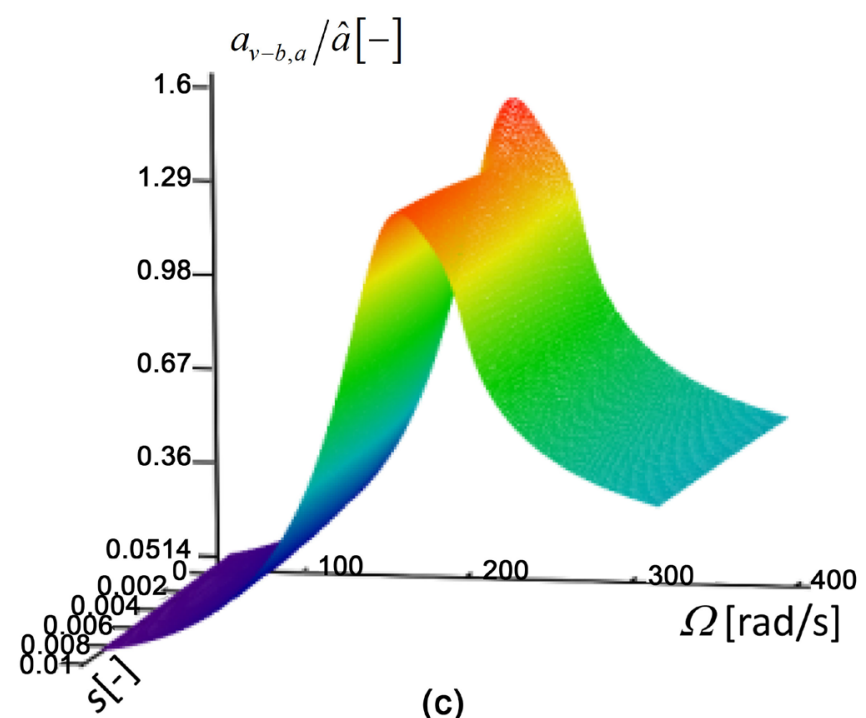

Figure 10. Related semi-major axis of the relative orbit for a rigid foundation: (a) mass eccentricity $\hat{e}_{u}$; (b) magnetic eccentricity $\hat{e}_{m} ;$ (c) bent rotor deflection $\hat{a}$.

The related semi-major axis of the relative orbit is shown in Figure 12.

\subsection{Discussion of the Results}

The influence of electromagnetic field damping can be shown, by variating the fundamental slip $s$. For $s=0$ no electromagnetic field damping occurs and for $s=0.01$, the electromagnetic field damping is maximal.

First, the vibrations for a rigid foundation (Figure 9 and Figure 10) are discussed. Regarding an excitation with rotor mass eccentricity $\hat{e}_{u}$ the influence of electromagnetic field damping on the vibrations is small, mostly leading to a slight shift of the resonances to higher rotor speeds (Figure 9(a) and Figure 10(a)). The reason is, that with increasing fundamental slip $s$ the electromagnetic spring constants $c_{m d}$ decreases (Figure 8(a)), which shifts the resonance to higher speeds. The drop of the vibration amplitudes in the resonances when increasing the fundamental slip $s$ (Figure 9(a) and Figure 10(a))-starting 


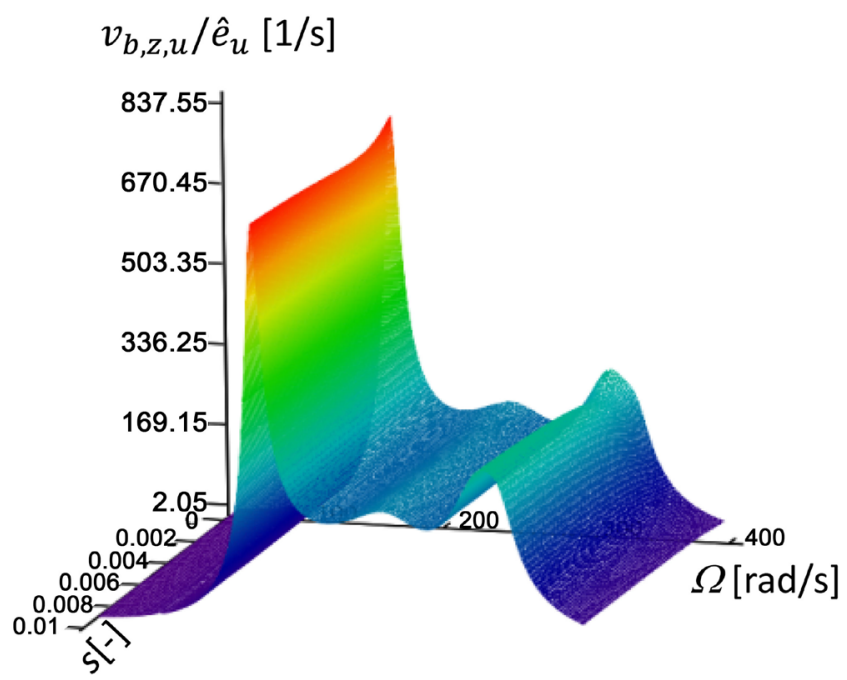

$v_{b, y, u} / \hat{e}_{u}[1 / s]$

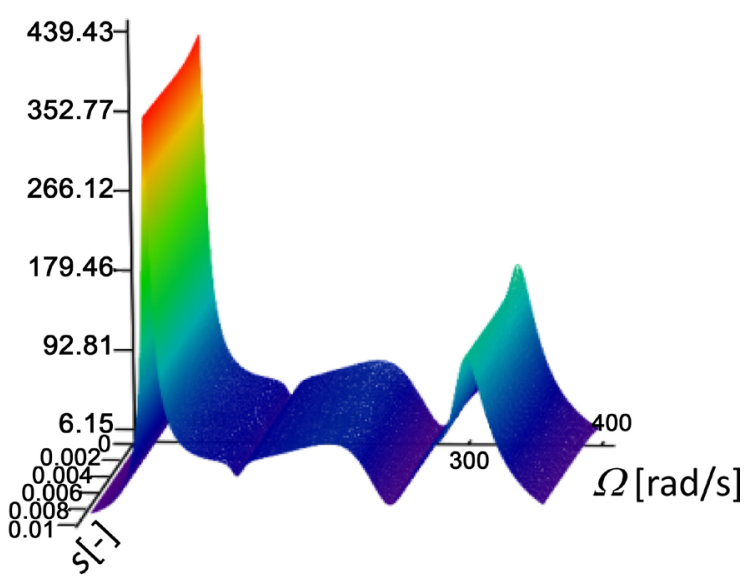

(a)
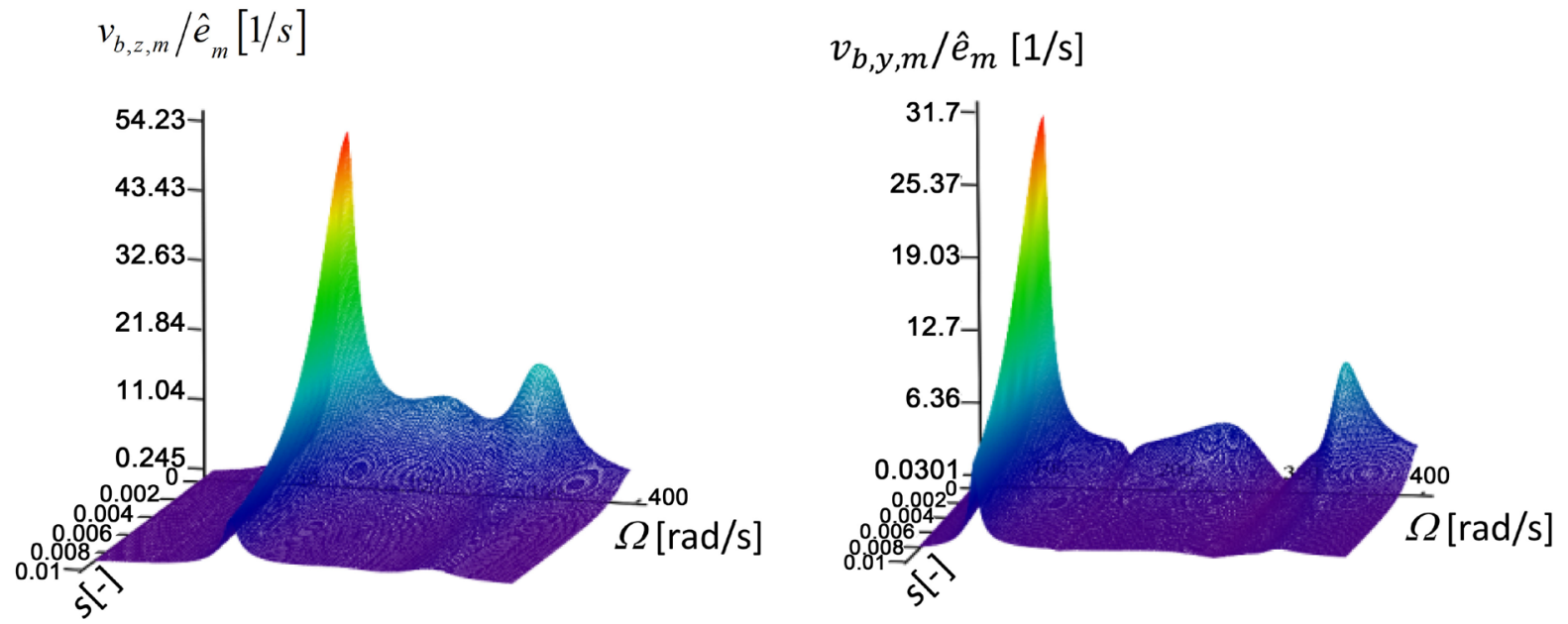

(b)
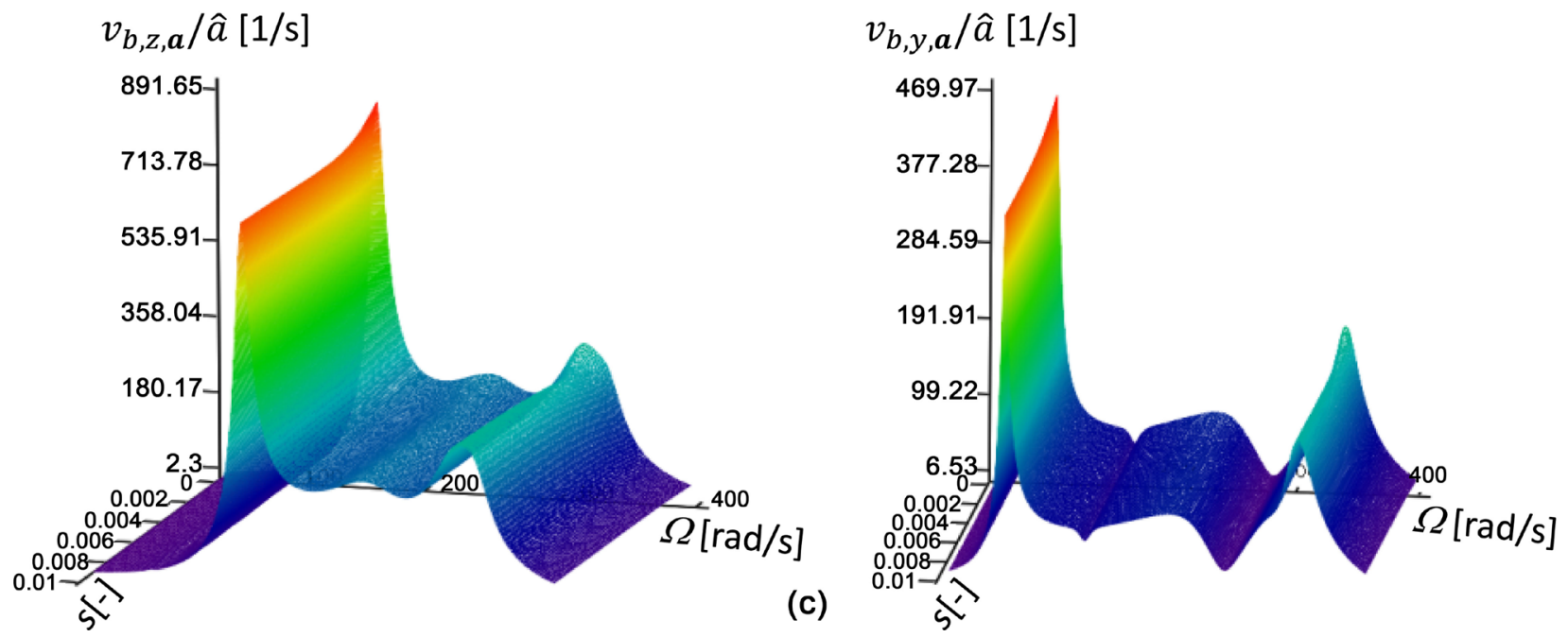

Figure 11. Related bearing housing vibration velocities for the soft foundation-z-direction (left diagram) and y-direction (right diagram): (a) mass eccentricity $\hat{e}_{u}$; (b) magnetic eccentricity $\hat{e}_{m} ;$ (c) bent rotor deflection $\hat{a}$. 


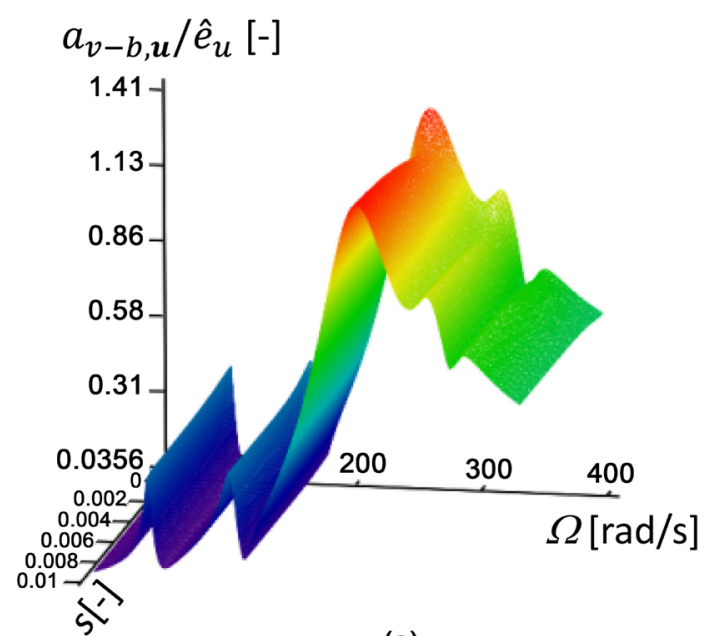

(a)

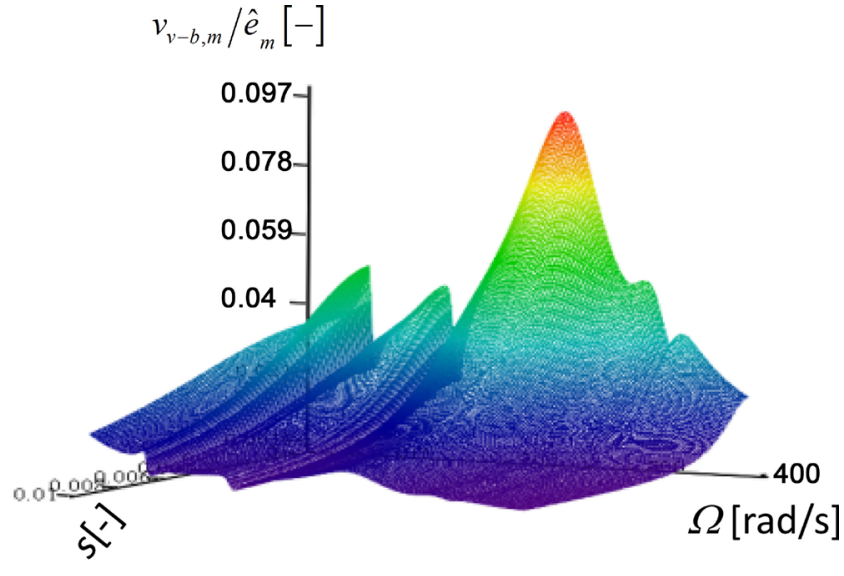

(b)

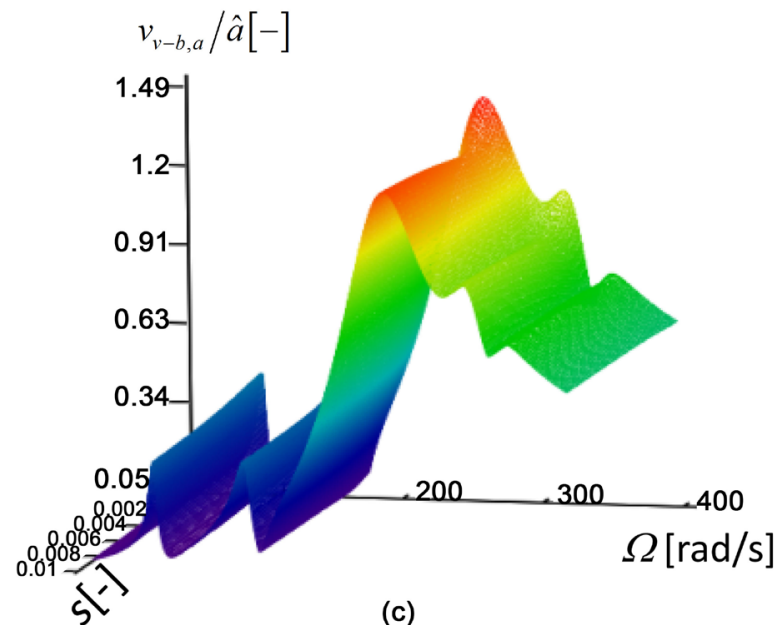

Figure 12. Related semi-major axis of the relative orbit for the soft foundation: (a) mass eccentricity $\hat{e}_{u}$; (b) magnetic eccentricity $\hat{e}_{m} ;$ (c) bent rotor deflection $\hat{a}$.

from $s=0$-is caused by the change of the electromagnetic damper constant $d_{m}$ (Figure 8(b)). For excitation by magnetic eccentricity $\hat{e}_{m}$ (Figure 9 (b) and Figure 10(b)) the influence of electromagnetic field damping on the vibrations is much stronger. The vibration amplitudes decrease strongly with increasing slip. The reason is that also the excitation is here depending on the electromagnetic spring constants $c_{m d}$, which can be seen in (23). With increasing fundamental slip $s$, the electromagnetic spring constants $c_{m d}$ decreases (Figure 8(a)), leading also to a decrease of the electromagnetic excitation force $\left(\hat{e}_{m} \cdot c_{m d}\right)$. Excitation by a bent rotor deflection $\hat{a}$ represents here a superposition of excitation by rotor mass eccentricity $\hat{e}_{u}$ and magnetic eccentricity $\hat{e}_{m}$, because the amplitudes $\left(\hat{e}_{u}=\hat{e}_{m}\right)$ and the phases $\left(\varphi_{u}=\varphi_{m}\right)$ are identical in this kind of analysis (Figure $9(\mathrm{c})$ and Figure $10(\mathrm{c})$ ).

For soft foundation (Figure 11 and Figure 12), the vibrations characteristic changes completely compared to operation on a rigid foundation. Additional resonances at low rotor speeds occur, where the motor acts nearly as a rigid body, and the existing resonances at rigid foundation are now shifted to higher 
speeds. The influence of electromagnetic field damping on the resonances at higher speeds is quite similar as for rigid foundation. However at lower speeds, a shift of the rigid body resonances due to electromagnetic field damping is not obvious, because rotor and stator act here on the soft foundation nearly as one mass, oscillating with each other. Vibrations caused by magnetic eccentricity $\hat{e}_{m}$ are here also strongly depending on the fundamental slip $s$, which can be clearly seen in Figure 11(b) and Figure 12(b). Excitation by a bent rotor deflection $\hat{a}$ is here again a superposition of excitation by rotor mass eccentricity $\hat{e}_{u}$ and magnetic eccentricity $\hat{e}_{m}$. For the bearing housing vibrations the rigid body resonances are here the worst case (Figure 11), because of the low damping of the foundation. However, for the relative shaft displacements (Figure 12) the resonances at higher speeds are much more critical than the resonances at lower speeds, because at higher speeds rotor and stator are oscillate against each other, whereas at lower speed rotor and stator are acting nearly as one mass.

\section{Conclusion}

The paper presents a mathematical multibody model of a soft mounted induction motor with sleeve bearings regarding forced vibrations caused by dynamic rotor eccentricities considering electromagnetic field damping. After the mathematical coherences have been shown, a numerical example was presented, where the bearing housing vibration velocities and the semi-major axes of the relative orbits between shaft journals and bearing housings have been analyzed for the different kinds of rotor eccentricity. By analyzing the vibrations for different fundamental slip $s$, the influence of electromagnetic field damping could be clearly shown. The aim of the paper is to present a method-based on a multibody model-for considering electromagnetic field damping for vibration analysis of a soft mounted induction motor, which can also be adopted in FE-Analysis.

\section{References}

[1] Rao, J.S. (1996) Rotor Dynamics. John Wiley \& Sons, New York.

[2] Vance, J.M., Zeidan, F.J. and Murphy, B. (2010) Machinery Vibration and Rotordynamics. John Wiley \& Sons, Inc., Hoboken, New Jersey.

https://doi.org/10.1002/9780470903704

[3] Gasch, R., Nordmann, R. and Pfützner, H. (2002) Rotordynamik. Springer-Verlag, Berlin-Heidelberg. https://doi.org/10.1007/3-540-33884-5

[4] Arkkio, A., Antila, M., Pokki, K., Simon, A. and Lantto, E. (2000) Electromagnetic Force on a Whirling Cage Rotor. IEE Proceedings-Electric Power Applications, 147, 353-360. https://doi.org/10.1049/ip-epa:20000523

[5] Stoll, R.L. (1997) Simple Computational Model for Calculating the Unbalanced Magnetic Pull on a Two-Pole Turbogenerator Rotor Due to Eccentricity. IEE Proceedings-Electric Power Applications, 144, 263-270.

https://doi.org/10.1049/ip-epa:19971143

[6] Belmans, R., Vandenput, A. and Geysen, W. (1987) Calculation of the Flux Density and the Unbalanced Pull in Two Pole Induction Machines. Archiv der Elektrotechnik, 70, 151-161. https://doi.org/10.1007/BF01574064 
[7] Seinsch, H.-O. (1992) Oberfelderscheinungen in Drehfeldmaschinen. Teubner, Stuttgart.

[8] Früchtenicht, J., Jordan, H. and Seinsch, H.O. (1982) Exzentrizitätsfelder als Ursache von Laufinstabilitäten bei Asynchronmaschinen. Archiv für Elektrotechnik, Bd. 65, Teil 1, Seite 271-281, Teil 2, Seite 283-292.

[9] Werner, U. (2016) Influence of Electromagnetic Field Damping on Forced Vibrations of Induction Rotors Caused by Dynamic Rotor Eccentricity. ZAMM-Journal of Applied Mathematics and Mechanics, 97, 38-59.

[10] Werner, U. (2010) Theoretical Vibration Analysis of Soft Mounted Electrical Machines Regarding Rotor Eccentricity Based on a Multibody Model,. Multibody System Dynamics, 24, 43-66. https://doi.org/10.1007/s11044-010-9190-2

[11] IEC 60034-14 (2007) Rotating Electrical Machines-Part 14: Mechanical Vibration of Certain Machines with Shaft Heights $56 \mathrm{~mm}$ and Higher-Measurement, Evaluation and Limits of Vibration Severity.

[12] ANSI/API 541 (2004) Form-Wound-Squirrel-Cage Induction Motors-500 Horse Power and Larger. API.

[13] ISO 10816-1 (1995) Mechanical Vibration-Evaluation of Machine Vibration by Measurements on Non-Rotating Parts-Part 1: General Guidelines (ISO 10816$1: 1995)$.

[14] ISO 7919-3 (2008) Mechanical Vibration-Evaluation of Machine Vibration by Measurements on Rotating Shafts-Part 3: Coupled Industrial Machines.

[15] Tondl, A. (1965) Some Problems of Rotor Dynamics. Chapman \& Hall, London.

[16] Lund, J. and Thomsen, K. (1978) A Calculation Method and Data for the Dynamics of Oil Lubricated Journal Bearings in Fluid Film Bearings and Rotor Bearings System Design and Optimization. ASME, New York, 1-28.

Submit or recommend next manuscript to SCIRP and we will provide best service for you:

Accepting pre-submission inquiries through Email, Facebook, LinkedIn, Twitter, etc. A wide selection of journals (inclusive of 9 subjects, more than 200 journals)

Providing 24-hour high-quality service

User-friendly online submission system

Fair and swift peer-review system

Efficient typesetting and proofreading procedure

Display of the result of downloads and visits, as well as the number of cited articles

Maximum dissemination of your research work

Submit your manuscript at: http://papersubmission.scirp.org/

Or contact jamp@scirp.org 